\title{
12
}

\section{Social dimensions of biodiversity conservation programs}

\author{
Saan Ecker
}

\section{Key lessons}

- Respond to landholder motivations for biodiversity conservation.

- Understand the socio-demographic profile of potential participants.

- Support those already making the change.

- Design programs to achieve compatibility between financial and biodiversity outcomes.

Social dimensions play an important role in landholder participation in natural resource management (NRM) programs. Many regional- and community-based NRM organisations have a good understanding of landholder characteristics and capacity from data collected through national, regional, or catchment scale landholder surveys and other social studies. But, often, NRM plans only include aspirations for integrating this data into program design, project communications and evaluation. While various frameworks have been developed to do this (Fenton 2004; Robins and Dovers 2007), there are few recorded cases where integration of social, environmental and economic information has been used to support successful implementation of NRM programs (Bammer et al. 2005). 
This chapter draws on two examples in which landholder characteristics were examined to gain insight into how specific NRM programs could be better implemented. The case studies used in this chapter are former Australian Government NRM programs: the Environmental Stewardship Program, and the Sustainable Farm Practice component of the Caring for our Country ( $\mathrm{CofC}$ ) initiative. A study into the motivations, drivers, and barriers associated with involvement in the Environmental Stewardship Program was undertaken at the beginning of the program. A longitudinal national survey on adoption and reasons for adoption was undertaken at the beginning and end of the Sustainable Farm Practice component of the CfoC initiative. Findings from these studies support five social dimensions considered important in the development and implementation of biodiversity conservation programs.

\section{Respond to landholder motivations for biodiversity conservation}

Human behaviour is complex. At the very least, decisions to act include the combined influences of behaviours, intentions, perceived behavioural control, attitude and societal norms (Fishbein and Ajzen 2010). Lack of understanding of what drives biodiversity conservation can lead to simplistic policies and potentially alienate possible participants. Effort in understanding landholders' complex motivations for biodiversity conservation is likely to benefit outcomes of biodiversity initiatives, particularly when this understanding is embedded in program design and extension.

For example, the national Drivers of Practice Change survey canvassed 1,400 commercial farmers to identify their motivations for adoption of sustainable land management practices which were promoted under the CfoC initiative (Ecker et al. 2012). The survey asked respondents to select one of three motivational areas (financial, environmental, and personal) for each practice. Farmers rated environmental factors as most frequently influencing their adoption of native vegetation management practices. Respondents selected up to three detailed statements for each motivational area (see Table 12.1). These provided insight into the diverse factors that farmers considered in facilitating adoption of these practices. 
Table 12.1: Most frequently selected motivational areas and motives for native vegetation management practices, listed in order of importance to respondents.

\begin{tabular}{|c|c|c|c|}
\hline & \multicolumn{3}{|c|}{ Motives } \\
\hline & Financial benefits & Environmental factors & Personal motivations \\
\hline $\begin{array}{l}\text { Motivational } \\
\text { area }\end{array}$ & $\begin{array}{l}\text { Provides shelter for } \\
\text { livestock } \\
\text { Increased land value } \\
\text { Increased returns/ } \\
\text { income }\end{array}$ & $\begin{array}{l}\text { Improves soil quality } \\
\text { Aligns with } \\
\text { environmental goals } \\
\text { and beliefs } \\
\text { Provides habitat for } \\
\text { fauna }\end{array}$ & $\begin{array}{l}\text { Desire to protect } \\
\text { natural resources } \\
\text { Desire to improve } \\
\text { amenity of the } \\
\text { landscape } \\
\text { Recognition by } \\
\text { neighbours and } \\
\text { community }\end{array}$ \\
\hline
\end{tabular}

Source: Ecker et al. (2012); Kancans et al. (2014).

The results from a different survey on landholder motivations for involvement in the Environmental Stewardship Program also demonstrated complex considerations influencing participation in conservation activities (Ecker and Thompson 2011). Financial motivations, environmental stewardship interests, prior conservation efforts, the opportunity to engage in a social network, and the opportunity to learn more about native vegetation management contributed to landholder participation in the program. Most respondents 'strongly agreed' that conservation and enhancement of native vegetation contributed to improved property or landscape health, aesthetics, soil stabilisation, and controlling rising water tables. Few thought that conservation and enhancement of native vegetation increased fire risk, and fewer saw it as an impediment to controlling pests and weeds. Understanding what actually motivates people to participate in biodiversity initiatives can assist with engagement strategies and lead to better communication and relationships with participants.

\section{Understand the socio-demographic profile of potential participants}

The farm business and farmer's personal characteristics are important to consider in program design of and stakeholder engagement with biodiversity protection initiatives. Social profiling has been widely used by regional NRM groups to better understand the 
socio-demographic profile of communities. However, the usefulness of this information depends on scale and the quality of data collection and its interpretation.

In the context of the CfoC initiative, Kancans et al. (2014) explored demographic and other adoption-related characteristics relevant to land management practices. Table 12.2 reflects the findings from a series of one-way analysis of variance, comparing the characteristics of adopters and non-adopters of each practice. These findings show that landholders more likely to conserve or manage native vegetation are older, well-educated, have a strong financial status, are a member of a land management group, and have prior involvement in a government land management initiative.

Table 12.2: Characteristics more likely to be found in adopters of specific land management practices.

\begin{tabular}{|l|l|l|l|}
\hline \multirow{2}{*}{} & \multicolumn{3}{|c|}{ Land management practice } \\
\cline { 2 - 4 } & $\begin{array}{l}\text { Native pasture } \\
\text { conservation or } \\
\text { management }\end{array}$ & $\begin{array}{l}\text { Native vegetation } \\
\text { conservation or } \\
\text { management }\end{array}$ & $\begin{array}{l}\text { Fencing native } \\
\text { vegetation }\end{array}$ \\
\hline Higher cash income & No & Yes & Yes \\
\hline Higher rate of return & No & Yes & Yes \\
\hline Larger farms & Yes & No & No \\
\hline Younger & No & No & No \\
\hline Higher level of education & Yes & Yes & Yes \\
\hline $\begin{array}{l}\text { Participate in } \\
\text { government program }\end{array}$ & Yes & Yes & Yes \\
\hline Participate in extension & No & No & No \\
\hline $\begin{array}{l}\text { Member of land } \\
\text { management group }\end{array}$ & Yes & Yes & Yes \\
\hline
\end{tabular}

Source: Kancans et al. (2014)

A landholder's previous experience with an NRM program has been shown to influence their involvement in a future conservation initiative (Windle and Rolfe 2006). Supporting this, Ecker and Thompson (2011) found that 45 per cent of applicants in the Environmental Stewardship Program had previously been involved in environmental or NRM programs, including financial and non-financial support. 
Farm income is often cited as an import driver of land management practice adoption, however, the influence of farm income on conservation adoption is ambiguous, as financial assistance from the NRM program may overcome farm income constraints (Cary et al. 2002). Another important aspect to understand is baseline knowledge in regard to conservation practices. Seventy per cent of Environmental Stewardship Program applicants said they had never undertaken training relevant to native vegetation conservation, and less than half could identify box gum grassy woodlands on their property (Ecker and Thompson 2011). Baseline information such as this can be useful for assessing enduring change in the long term.

\section{Support those already making the change}

There is evidence that external support sources are secondary to intrinsic motivations in NRM decisions. For example, Farmar-Bowers and Lane (2006) suggest that farmers use a number of lenses when seeking and identifying an opportunity, starting with personal motivations related to the opportunity (intrinsic interests, family considerations, and personal knowledge), before moving onto external components, such as knowledge and support. It is likely that support is associated with increasing capacity to implement new management practices once landholders have decided to adopt. This is the point at which they seek support. The implication is that support is better received by those who have made the decision to implement the practice. As obvious as it sounds, this thinking is not always embedded in policy and program approaches.

Lending some support to this concept, Ecker and Thompson (2011) found that the majority of participants applying for the Environmental Stewardship Program had previously participated in conservation activities, with more than 80 per cent saying they had revegetated parts of their property, and more than half having fenced remnant vegetation. Repeat customers may be frowned upon in program evaluations, as there is often a preference within the program to attract new participants. Targeting landholders who are ready and able to make changes, and support the improvement of biodiversity values over time, may be a more realistic and efficient target. This is supported by Greiner and Gregg (2011), who demonstrated that landholders 
with higher intrinsic motivation (i.e. higher scores for 'lifestyle and stewardship motivation') had undertaken more conservation action on their properties.

Ecker et al. (2012) outlined the role that support providers play in influencing landholder decisions to adopt land management practices. Non-financial support played a secondary role to financial, environmental, and personal motivations in decisions to adopt NRM activities. Relatively few respondents ( 9 per cent) said the availability of non-financial support influenced them in land management practice decisions 'to a great extent'. While support is of critical importance in maintaining the impetus for adoption of native vegetation management, these findings suggest that support is generally accessed after the decision to adopt the practice is made.

\section{Recognise the importance of community- based conservation and NRM organisations}

Community-based groups, such as regional NRM groups (often a mix of government and community), Landcare, catchment, conservation and other care groups, maintain momentum and continuity between shifts in government policies. As noted in Chapter 5, environmental NGOs are often more focused on on-ground activities and, as such, are in the best position to facilitate between individuals and national environmental challenges. When the groups adequately represent social catchments, they provide foci and forums for NRM in the community. While the importance of community-based groups is well covered in the literature (e.g. Marshall 2010), quantitative measures that provide substantive evidence of the importance of these groups is harder to come by.

Results of the national Drivers of Practice Change survey on farmer motivations for sustainable land management practices, administered in 2010 and 2012, demonstrated the importance of community groups in supporting landholders' adoption of native vegetation management practices from three different survey questions. First, Landcare or farmer production groups were found to be the most important influence on native vegetation management adoption (Ecker et al. 
2012; Kancans et al. 2014). Second, of the 27 per cent of adopters who sought non-financial support, over half said they obtained this support from Landcare groups, followed by catchment management authorities (CMAs) (20 per cent). Third, as shown in Table 12.2, members of NRM groups, including community- and production-focused groups, were more likely to adopt native vegetation management practices than non-members (Kancans et al. 2014).

Ecker and Thompson (2011) also found that around 60 per cent of participants involved in the Environmental Stewardship Program indicated that CMAs are an important information source when making decisions to conserve native vegetation. They considered CMAs more important than any other information source. The importance of Landcare as a source of information to participants was also evident: 44 per cent of the participants indicated that Landcare groups were important in their decision-making processes related to native vegetation management. The influence of these communitybased groups is moderated by factors such as longevity and degree of connection with the community.

A relationship with non-government NRM and conservation organisations, through both regular (e.g. extension) and irregular (e.g. forums and events) interactions, and the degree of trust held and the valuing of this support provision is known to affect landholders involvement in land management programs (Jennings 2005). Landcare groups and other community-based organisations, such as regional NRM groups and CMAs, established in the community are well positioned to deliver or partner with other delivery agents in biodiversity program design and implementation, and have an important role to play in the long-term success of these initiatives.

\section{Design programs to achieve compatibility between financial and biodiversity outcomes}

A profitable farming enterprise is an important goal for farmers. It is important that biodiversity conservation initiatives consider this goal in program design and extension. The phrase 'need to be in the black to be in the green' is popular amongst farmers. The first strategy in this 
chapter emphasised the interrelatedness of financial, environmental, and personal motivations. While the environmental stewardship motivations of those involved in biodiversity conservation are clear, a balance between environmental and financial outcomes is important for some farmers.

Lockie and Tennent (2010) note issues with previous schemes included an inability to coherently link farm operations and biodiversity outcomes. In the study by Ecker and Thompson (2011), participants said that the Environmental Stewardship Program had succeeded in linking production farming and biodiversity outcomes through the flexibility allowed for productive use of conservation areas under certain circumstances. Landholders who rely on farm income need to have adequate flexibility to manage drought conditions and other tough financial periods. Participants in the study were generally well informed about the impacts and benefits of different grazing regimes on both biodiversity outcomes and profit, including understanding the importance of having functioning grassy woodland ecosystems in managing livestock through these tough periods. Many participants indicated that they had reduced stocking numbers in order to maintain native pastures, and that in some cases this had improved the quality of wool and lambing percentages. Encouraging debate, discussion, and shared learning on how to best maximise profit and conservation outcomes, and subsequent incorporation of this information into program design is important in ensuring the long-term success of biodiversity initiatives.

\section{Summary}

This chapter draws on recent studies on landholder adoption of biodiversity conservation programs to lend support to five key strategies that are important in ensuring the success of such initiatives: respond to landholder motivations for biodiversity conservation; understand the socio-demographic profile of potential participants; support those already making the change; recognise the importance of community-based conservation and NRM organisations; and design programs to achieve compatibility between financial and biodiversity outcomes. These strategies relate to understanding and responding to the complex human ecology of participation in biodiversity initiatives 
where financial, environmental and personal factors interrelate to enhance or impede this participation. While past NRM programs have adopted some of these strategies, rarely are all these factors considered in program design. Time spent in improving the understanding of the target audience, building a strong community-based support network, recognising past initiatives, and piloting the program prior to broadscale implementation is time well spent. These five strategies, amongst the other insights recorded in this book, can help towards building effective approaches to achieve successful biodiversity outcomes that benefit both environment and society.

\section{References}

Bammer, G., C. Mobbs, R. Lane, S. Dovers and C. Allan (2005) An introduction to Australian case studies of integration in natural resource management', Australasian Journal of Environmental Management 12 (supplementary issue).

Cary, J., T. Webb and N. Barr (2002) 'Understanding land managers' capacity to change to sustainable practices: Insights about practice adoption and social capacity for change', Bureau of Rural Sciences, Canberra.

Commonwealth of Australia (2002) National natural resource management capacity building framework, Department of Agriculture, Fisheries and Forestry and Environment and Heritage, Canberra.

Cullen, P. (2004) 'Using local and scientific knowledge to inform catchment management', presentation to Upper Murrumbidgee Catchment Coordinating Committee Biennial Natural Resource Management Forum, 29 September, University House, The Australian National University, Canberra.

Ecker, S. and L.J. Thompson (2011) Participation in the Environmental Stewardship Program Box Gum Grassy Woodlands Project: key findings and implications, ABARES report to client for the Department of Sustainability, Environment, Water, Population and Communities, Canberra. 
Ecker, S., L. Thompson, R. Kancans, N. Stenekes, and T. Mallawaarachchi (2012) 'Drivers of practice change in land management in Australian agriculture', ABARES, Department of Agriculture, Fisheries and Forestry, Canberra.

Farmar-Bowers, Q. and R. Lane (2006) Understanding farmer decision systems that relate to land use, Department of Sustainability and Environment, Victoria, report to the School of Global Studies, Social Sciences and Planning, RMIT, Melbourne.

Fenton, D.M. (2004) A monitoring and evaluation framework for the social dimensions of the NHT and NAPSWQ, National Land and Water Resource Audit, Canberra.

Fishbein, M. and I. Ajzen (2010) Predicting and changing behavior: The reasoned action approach, New York, Taylor \& Francis.

Greiner, R. and D. Gregg (2011) 'Farmers' intrinsic motivations, barriers to the adoption of conservation practices and effectiveness of policy instruments: Empirical evidence from northern Australia', Land Use Policy 28: 257-65.

Jennings, J. (2005) On the Effectiveness of Participatory Research in Agriculture, PhD thesis, University of Western Sydney.

Kancans, R., S. Ecker, A. Duncan, N. Stenekes and H. Zobel-Zubrzycka (2014) Drivers of practice change in Australian agriculture: Synthesis report: Stages I, II and III, Australian Government Department of Agriculture, Canberra.

Lockie, S. and R. Tennent (2010) 'Market instruments and collective obligations for on-farm biodiversity conservation', Agriculture, Biodiversity and Markets Livelihoods and Agroecology in Comparative Perspective (eds S. Lockie and D. Carpenter), Earthscan, London.

Marshall, G.R. (2010) 'What "community" means for farmer adoption of conservation practices', Changing land management: Adoption of new practices by rural landholders (eds D. Pannell and F. Vanclay), CSIRO Publishing, Melbourne. 
Pannell, D.J., G.R. Marshall, N. Barr, A.F.V. Curtis and R. Wilkinson (2006) 'Understanding and promoting adoption of conservation technologies by rural landholders', Australian Journal of Experimental Agriculture 46(11): 1407-24.

Robins, L. and S. Dovers (2007) 'NRM regions in Australia: The haves and the have nots', Geographical Research 45(3): 273-90.

Rogers, E. (2003) Diffusion of Innovations, fifth edition, Simon and Schuster, London.

Windle, J. and J. Rolfe (2006) Fitzroy Basin Association's Biodiversity Tender: An outline and evaluation, Central Queensland University, Rockhampton. 
This text is taken from Learning from agri-environment schemes in Australia: Investing in biodiversity and other ecosystem services on farms, edited by Dean Ansell, Fiona Gibson and David Salt, published 2016 by ANU Press, The Australian National University, Canberra, Australia. 